\title{
Anisotropically Consolidated Undrained Compression Test on Residual Soil
}

\author{
Jun Xian Lim ${ }^{1}$, Siaw Yah Chong ${ }^{1 *}$, Yasuo Tanaka ${ }^{1}$ and Min Lee Lee ${ }^{2}$ \\ ${ }^{1}$ Lee Kong Chian Faculty of Engineering and Science, Universiti Tunku Abdul Rahman, 43000 \\ Kajang Selangor, Malaysia \\ ${ }^{2}$ Department of Civil Engineering, Faculty of Engineering, University of Nothingham Malaysia, \\ 43500 Selangor, Malaysia
}

\begin{abstract}
In Malaysia, the shear strength and corresponding deformation characteristics of residual soils are normally investigated by isotropically consolidated undrained (CIU) triaxial test. In the present study, anisotropically consolidated undrained compression (CAU) tests were carried out and explored in an attempt to facilitate understanding on the fundamental behaviours of a selected residual soil. A triaxial apparatus setup which was capable of performing the CAU test was first developed. Through a monotonic strain-controlled triaxial test apparatus, soil properties and stress paths could be obtained experimentally. It was confirmed that the newly fabricated triaxial apparatus could provide reasonable experimental results. As distinguished from the isotropically consolidated undrained compression (CIU) test, anisotropic stresses were induced in the stress path test. It follows that the soil responses were different between the CIU and CAU tests. The coefficient of earth pressure at rest $(\mathrm{Ko})$ values as obtained in the present experiment showed a good agreement with the values estimated using equation reported by Jaky (1948).
\end{abstract}

\section{Introduction}

Malaysia, being a tropical country with warm and humid climatic conditions, has abundant tropical residual soils covering the superficial land area. Residual soils are known to be composed of a mixture of sand to clay particles and formed at the place of weathering. Therefore, the formation and behaviour of residual soils are highly different from the transported soil. Residual soil can be found in many countries worldwide, such as South Africa, Nigeria, Hong Kong, Singapore, Malaysia, United States, Brazil, and etc [2]. Previous research works have been conducted on the hydraulic properties, drained/ undrained shear strength, compressibility, and stiffness.

In practice, a wide variety of geotechnical projects involving the tropical residual soils in this country can be seen. These include slope design, embankment construction, and etc [2]. Although many researches pertaining to the mechanical behaviours of residual soils

\footnotetext{
* Corresponding author: chongsiawy@utar.edu.my
} 
have been widely reported from different parts of the world, a great number of the studies in Malaysia have only focused on the characteristics as well as mineralogy of residual soils. The laboratory investigations of fundamental mechanical behaviour and properties (i.e. shear strength and deformation properties) for residual soil are considered very limited as compared to the sand and clay. Recently, Salih and Kassim (2012) conducted a triaxial compression test on a remoulded tropical residual soil, which was sampled from a shallow soil deposit and then prepared by compaction method in the laboratory. Studies on the shear strength properties of tropical residual soils in Malaysia and Singapore were also explicitly covered by other researchers $[4,5,6]$.

As a replication of a soil state in an embankment in-situ, static or dynamic compaction of soil specimen was often employed in the laboratory. In reality, a soil element underneath the soil deposit is subjected to a vertical overburden stress and confined by an all-round radial stress, which is normally smaller than the vertical stress. Under zero lateral strain condition, a ratio between the effective lateral and effective vertical stresses is defined as the coefficient of lateral earth pressure at-rest $(K o)$. It was anticipated that the compacted soil specimen was inherent with a particular structure during the preparation stage. It follows that deeper understanding can be grasped from the responses of isotropicallyconsolidated and anisotropically-consolidated (i.e. one-dimensional consolidation) triaxial shear tests [7]. In Singapore, the soil responses under Ko condition have recently been studied in detail by several researchers $[5,6,13,15]$.

\section{Experimental setup}

Fig. 1 shows the schematic diagram of the triaxial cell apparatus used in the present study. The cell pressure was controlled by using an Electro-Pneumatic transducer from which the desired level of pneumatic air pressure could be supplied after receiving analogue signal from the computer. The strain-controlled loading system can be loaded with a very slow rate of straining (as small as $0.01 \%$ per minute). During the monotonic triaxial test, pore water pressure can be measured by using the pore water pressure transducer while the volume change load cell was developed to measure the volumetric deformation of a saturated soil specimen when it was stressed.

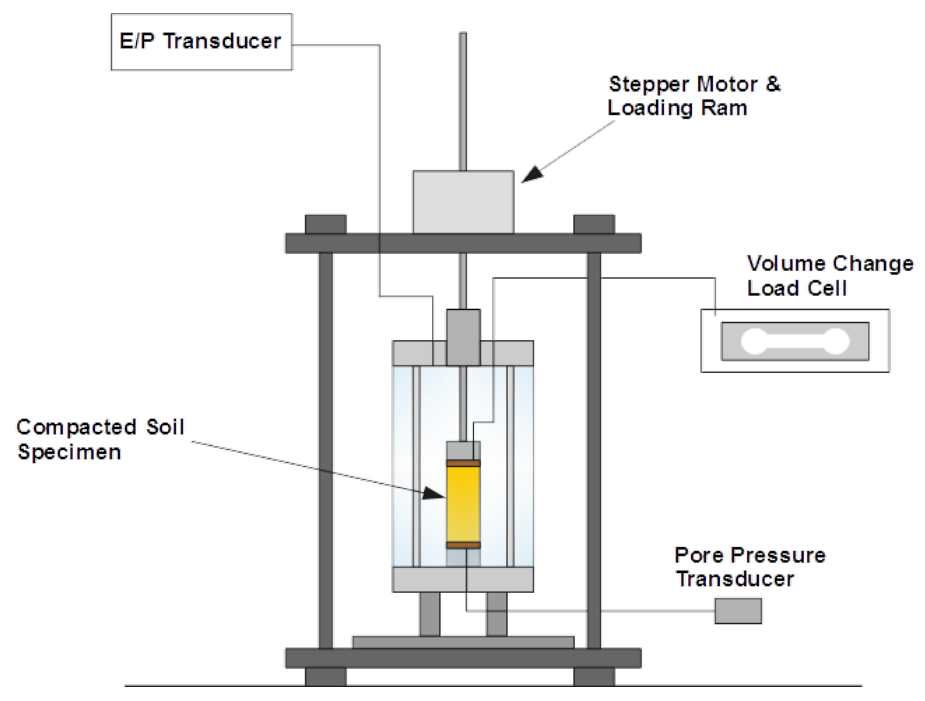

Fig. 1. Schematic diagram of triaxial cell apparatus 


\section{Methodology}

In this study, a tropical residual soil was sampled from a construction site at Bandar Sungai Long area in Peninsular Malaysia. The disturbed soil samples were collected from the superficial layer of soil deposit in the field. Prior to the main experiment, the soil specimen was prepared by manual compaction until a desired volume of triaxial specimen was attained $(50 \mathrm{~mm}$ in diameter and $100 \mathrm{~mm}$ in height). The soil specimen was prepared with a maximum dry density of $1750 \mathrm{~kg} / \mathrm{m}^{3}$ and an optimum moisture content of $16 \%$. During the soil compaction process, a steel tamper was used to compact the successive soil layers manually. Table 1 shows the details of physical properties for the soil specimens being tested.

Table 1. Details of Soil Specimens.

\begin{tabular}{|c|c|c|c|c|}
\hline Specimen & $\begin{array}{c}\text { Bulk Density } \\
\left(\mathrm{Kg} / \mathrm{m}^{3}\right)\end{array}$ & $\begin{array}{c}\text { Moisture } \\
\text { Content }(\%)\end{array}$ & Void Ratio & $\begin{array}{c}\text { Degree of } \\
\text { Saturation (\%) }\end{array}$ \\
\hline M1 \& CIU & 2035.5 & 16 & 0.510 & 83.11 \\
\hline D1 & 2071.5 & 16 & 0.484 & 87.60 \\
\hline D2 & 2068.6 & 16 & 0.475 & 89.30 \\
\hline
\end{tabular}

As residual soil is a mixture of sand and clay having appreciable amount of fine contents (residual soil studied in this experiment composed of nearly $40 \%$ of fine content), satisfactory degree of saturation is pragmatically difficult to be achieved by the application of high back pressure (i.e. $700-800 \mathrm{kPa}$ ) alone. Therefore, the double-vacuuming saturation method was adopted to facilitate the saturation process in the experiment. This alternative saturation method has been explicitly carried out and suggested by many researchers [8-11]. The soil specimens were first treated using double-vacuuming saturation process in order to achieve satisfactory saturation prelude to the monotonic triaxial tests.

After the saturation process, $B$-bar test was carried out by closing the drainage valve and monitored the increase of pore water pressure with respect to the increase of total cell pressure being applied incrementally. In the early stage of this experiment, however, the $B$ value was found to be $90 \%$ only and therefore it was still not considered to be satisfactorily saturated. Although the degree of saturation was slightly lower than the commonly-adopted threshold value (i.e. $95 \%$ ), the soil specimen was still examined in the newly-developed monotonic triaxial test apparatus and it was further compared with the experimental results of saturated soil specimen. After the first attempt following the saturation procedure recommended by [11], the following modifications were made for improvement and it was later realized to be promising to facilitate acceptable degree of saturation for residual soil.

To improve the saturation process, the bottom part of soil specimen was also subjected to vacuum pressure before the air burble was removed from the top of soil specimen. Then, de-aired water was allowed to percolate slowly from the base towards the top of soil specimen through hydraulic gradient. In $B$-bar test, the back pressure was adjusted to 150 $\mathrm{kPa}$ and two additional increments of cell pressure were applied. After several attempts, it was realized that a minimum back pressure of $150 \mathrm{kPa}$ indeed can favour the saturation process by dissolving the air burble into the water and the larger air burble may possibly become tiny one. The degree of saturation was found to reach $95 \%$ and therefore the double vacuuming saturation process was considered acceptable, especially for stiff compacted residual soil having considerable amount of fine content. In future, it is suggested to modify the configuration of top cap and base pedestal in order to have radial annular grooves that can ease the removal of air burble.

Then, Ko consolidation test and undrained compression test were conducted by using the developed triaxial apparatus. In the $K o$ consolidation test, one-dimensional 
consolidation condition could be achieved by either manually adjusting the cell pressure in order to compensate with the area change of soil specimen or controlling the cell pressure through sending analogue signal to the E/P transducer continuously. Finally, undrained compression test was carried out by closing the drainage valve and loaded slowly whilst the change of pore water pressure was measured in the course of time.

\section{Result and discussion}

After the double-vacuuming saturation process and the $B$-bar check, the soil specimen was subjected to one-dimensional consolidation and undrained compression tests. The experimental results were discussed as shown below.

\subsection{Ko consolidation stage}

In the present study, the one-dimensional consolidation was conducted at a very slow rate of loading $(0.02 \% / \mathrm{min})$. [12] conducted a series of standard triaxial compression and extension tests on Kaolin clay with a strain rate of $0.2 \%$ per minute. It follows that the same strain rate being employed in the present study can reasonably be used to investigate the mechanical behaviour of soil. The low strain rate in Ko consolidation was applied in order to avoid the development of excess pore water pressure when the drainage valve was open to allow consolidation for the soil specimen.

The Ko consolidation test was initiated by applying positive deviator stress (i.e. compression) whilst maintaining the cross-sectional area of the soil specimen by adjusting the cell pressure. The cell pressure was increased to compensate for the increase of crosssectional area of specimen, and vice versa. Through adjustment of cell pressure, the condition of zero lateral deformation (i.e. Ko consolidation) was able to be achieved in this experiment. It follows that the induced principal effective stresses $\left(\sigma_{1,}^{\prime} \sigma_{2}\right.$, and $\left.\sigma^{\prime}{ }_{3}\right)$ and the coefficient of lateral earth pressure $(\mathrm{Ko})$ were obtained. Upon reaching certain stress level, the vertical stress was reduced by reversing the direction of linear movement of loading ram slowly. The specimen was thus unloaded to reach the over-consolidated state, with an over-consolidation ratio (OCR) of about seven. Finally, the soil specimen was reloaded again by increasing the vertical stress until reaching normally-consolidated state at a stress level of about $391 \mathrm{kPa}$.

The stated loading sequence can be traced by referring to Fig. 2 in which the change of void ratio with respect to the vertical effective stress was presented. As compared to Kaolin clay or sand specimens, the compacted soil specimen prepared in this study had a much lower void ratio and was therefore considered having a denser soil state. Three soil specimens were tested and denoted as M1, D1, and D2, respectively. M1 specimen was and the first attempt in which testing data was recorded manually, whist D1 and D2 specimens were controlled with the aid of E/P transducers during the Ko consolidation test. It is worth mentioning that the M1 soil specimen had only reached $90 \%$ of degree of saturation while D1 and D2 were satisfactorily saturated. In addition, a set of CIU data was included in the present study to compare with the testing results of CAU test as obtained from the three specimens. 


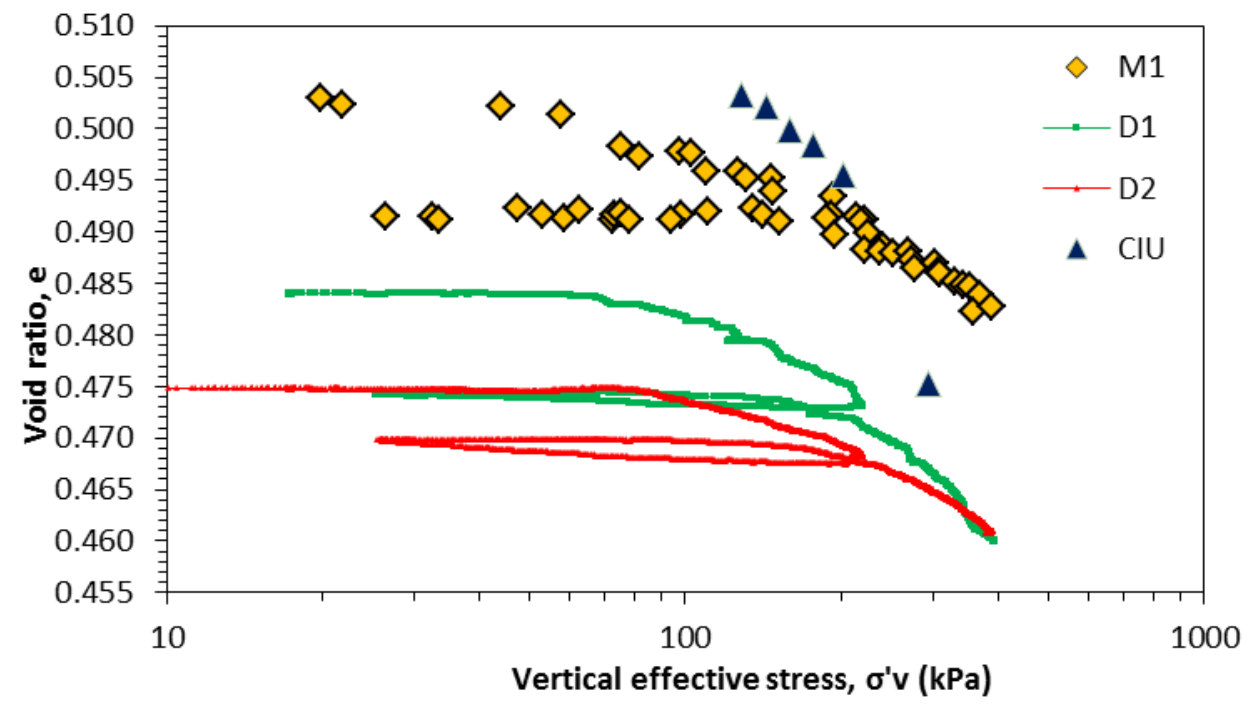

Fig. 2. Relationship between void ratio and vertical effective stress.

Fig. 3 resembles the features of $K o$ consolidation by using the developed triaxial apparatus. The experimental results of $K o$ consolidation were conventionally presented in such a way that $K o$ values were plotted with respect to the applied stress levels or axial strain levels $[13,14,15]$. At the initial transition period, there was a sharp reduction in $K o$ values for both loading and reloading stages. It is worth mentioning that initial isotropic stress state was unable to be obtained in the present study prior to the Ko consolidation test. This is because of the incompatible control between the vertical and radial effective stresses. At the beginning of the Ko consolidation, additional vertical stress through the loading ram was not adjusted accurately corresponding to the cell pressure being applied. It follows that the $\mathrm{Ko}$ value ranged from 2 to 2.5 at the beginning of consolidation test.

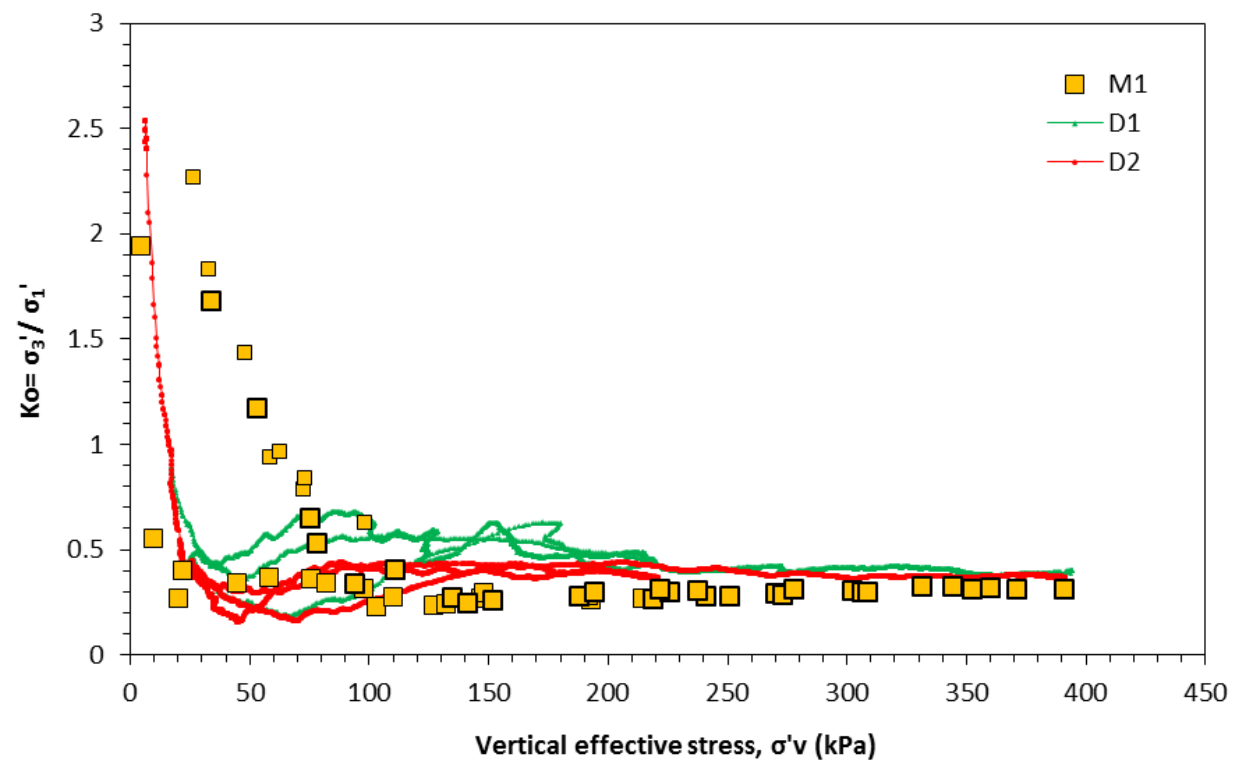

Fig. 3. Relationship between $K o$ and vertical effective stress. 
Fig. 4 depicts the relationship between $K o$ and Over-consolidation ratio (OCR) during the unloading and reloading stages of $K o$ consolidation. To have a clearer understanding on the influence of OCR towards Ko, a slower rate of loading should be used. This is because the adjustments of cell pressure and vertical stress were not independently controlled in this experiment.

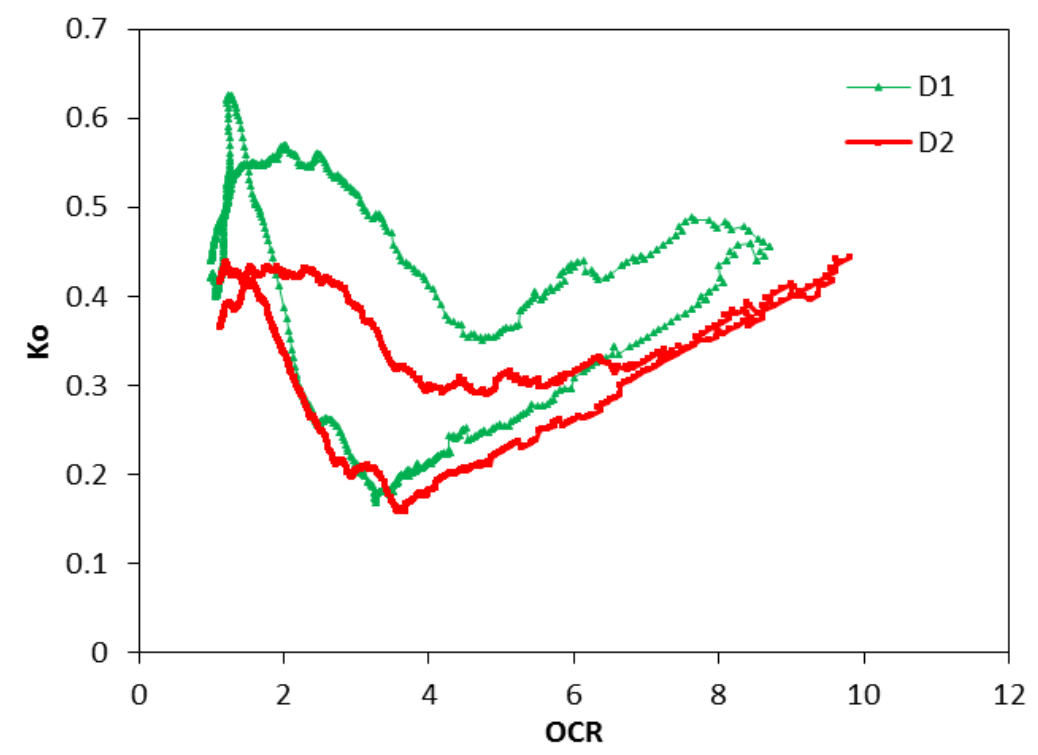

Fig. 4. Relationship between Ko and OCR during unloading and reloading.

[13] also reported a similar experimental results in which there is an initial sharp decrease in the $K o$ values when the soil specimen was compressed from initial isotropic stress state (i.e. Ko value equals unity) towards a desired $K o$ stress state. In addition, it seems to have a minimum stress point in the soil response before the soil was recompressed to reach normally-consolidated state. The minimum stress point may suggest that the soil specimen was anisotropically compressed to inherent with a particular soil structure [13]. In this case, the $K o$ value obtained in normally-consolidated state was in the range of $0.3-$ 0.4 . The Ko value at normally-consolidated state is thought to be influenced by many factors, such as the apparatus of testing, soil type, preparation method of soil specimen, density, and etc. In the work of [13], the reported $K o$ values of a marine dredged sand were found to be in the range of $0.33-0.46$. Besides that, [12] reported a $K o$ value of 0.66 for Kaolin clay.

Moreover, Fig. 5 depicts the change of horizontal effective stress with respect to the vertical effective stress during the Ko consolidation. The result was comparable to the simplified stress history of soil under Ko consolidation [16]. It can be seen from the figure that there is somewhat a constant ratio between the horizontal effective stress and the vertical effective stress along the normal consolidation line. Also, a loop was formed as a result of unloading and reloading. 


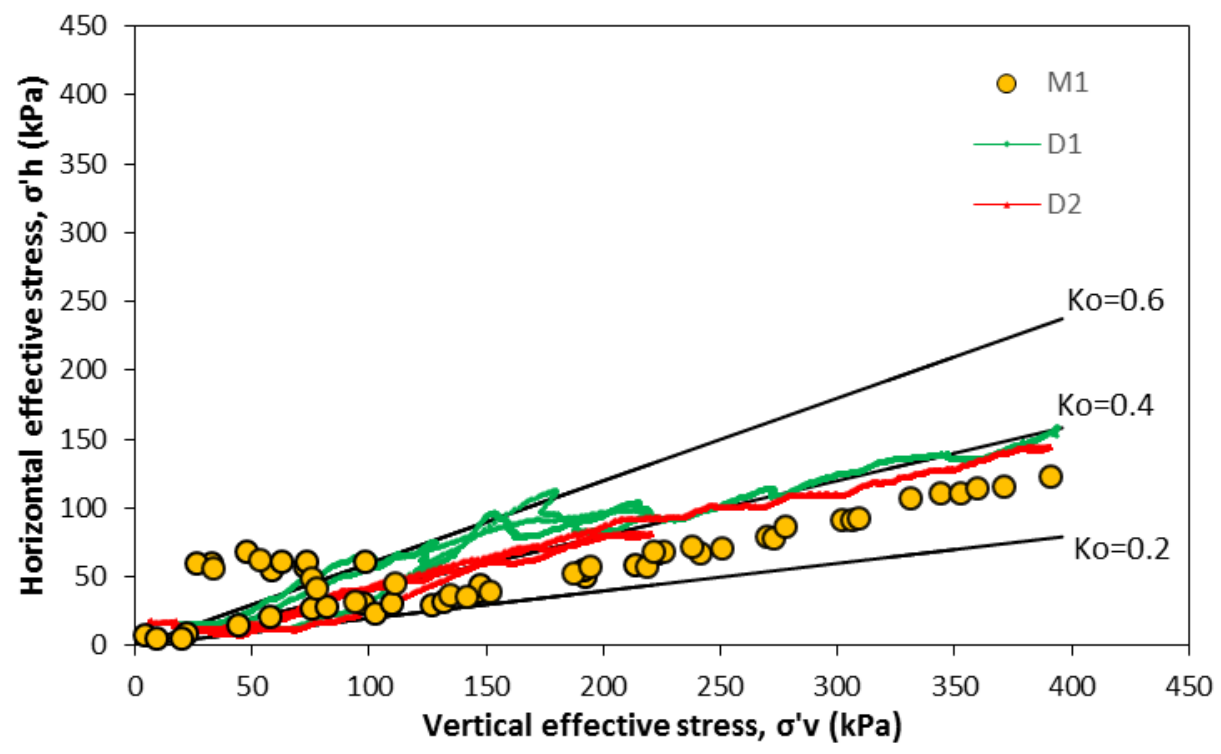

Fig. 5. Relationship between horizontal effective stress and vertical effective stress.

\subsection{Results during undrained shear}

Since the soil specimen had been subjected to Ko consolidation, the undrained compression test was initiated with certain magnitude of deviator stress. In fact, Ko-consolidated specimen was coupled with the natures of compression and shearing [17]. It should be noted that there was a slight decrease in deviator stress at the end of Ko consolidation due to a small deformational effect of soil specimen when the loading ram's compression was stopped. The deviator stress increased gradually $(0.1 \% / \mathrm{min})$ during the standard undrained compression test in which the axial stress was increased and the radial stress (i.e. cell pressure) was remained.

Figure 6 and 7 depict the typical stress-strain responses of the compacted residual soil in CAU and CIU tests, respectively. It should be noted that the responses of Ko consolidation as well as undrained shearing were both included in Fig. 6 for more complete result presentation. For the soil specimen being examined in the CAU test, pore water pressure developed rapidly at the commencement of undrained shearing stage. The deviator stress rapidly reached its peak stress value before approaching the critical state. As compared to the stress-strain response of CIU test, it was found that the soil tested anisotropically showed a "peak" deviator stress. It seems that the soil from CAU test behaves as similar to over-consolidated clay (or dense sand) as the "peak" deviator stress was usually observed [17] during the undrained compression test. On the other hand, the soil from CIU test gave rise to a relatively flat stress-strain response and the behaviour was similar to the normallyconsolidated clay (or loose sand). For CIU test, substantial positive pore water pressure was developed after specimen was isotropically consolidated to $200 \mathrm{kPa}$ of mean effective principle stress and undergoing undrained compression. 


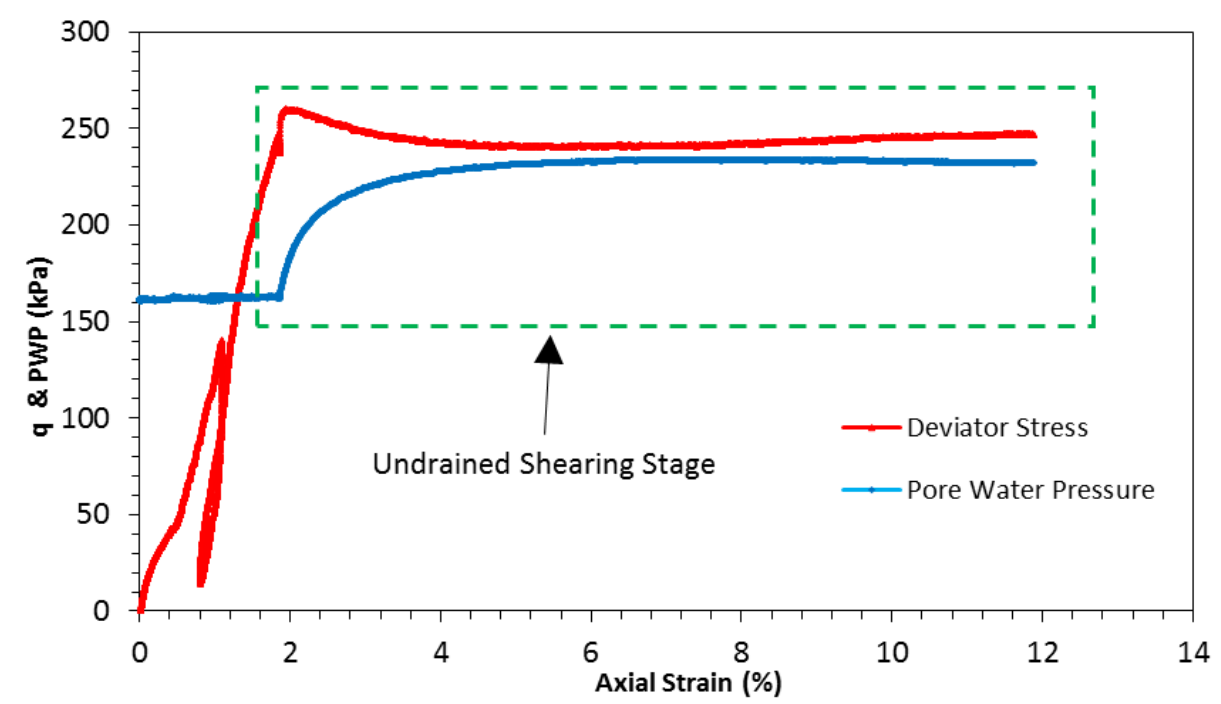

Fig. 6. Typical Stress-Strain Response in CAU test.

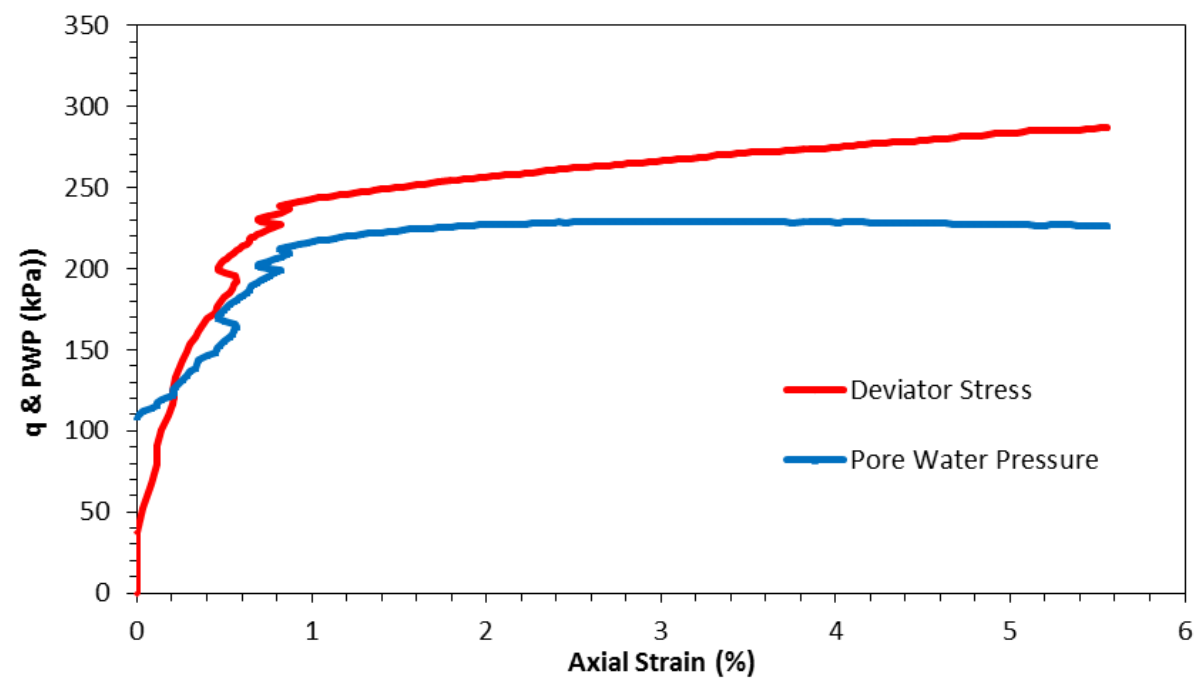

Fig. 7. Typical Stress-Strain Response in CIU test.

Fig. 8 shows the effective stress path as obtained from the Ko consolidation and undrained compression tests. As distinguished from the isotropically consolidated soil specimen, in which case the effective stress path travel to the left against the total stress path, the soil was initially anisotropically stressed proportionally in Ko consolidation before development of excess power water pressure to reach a critical state in the end. 


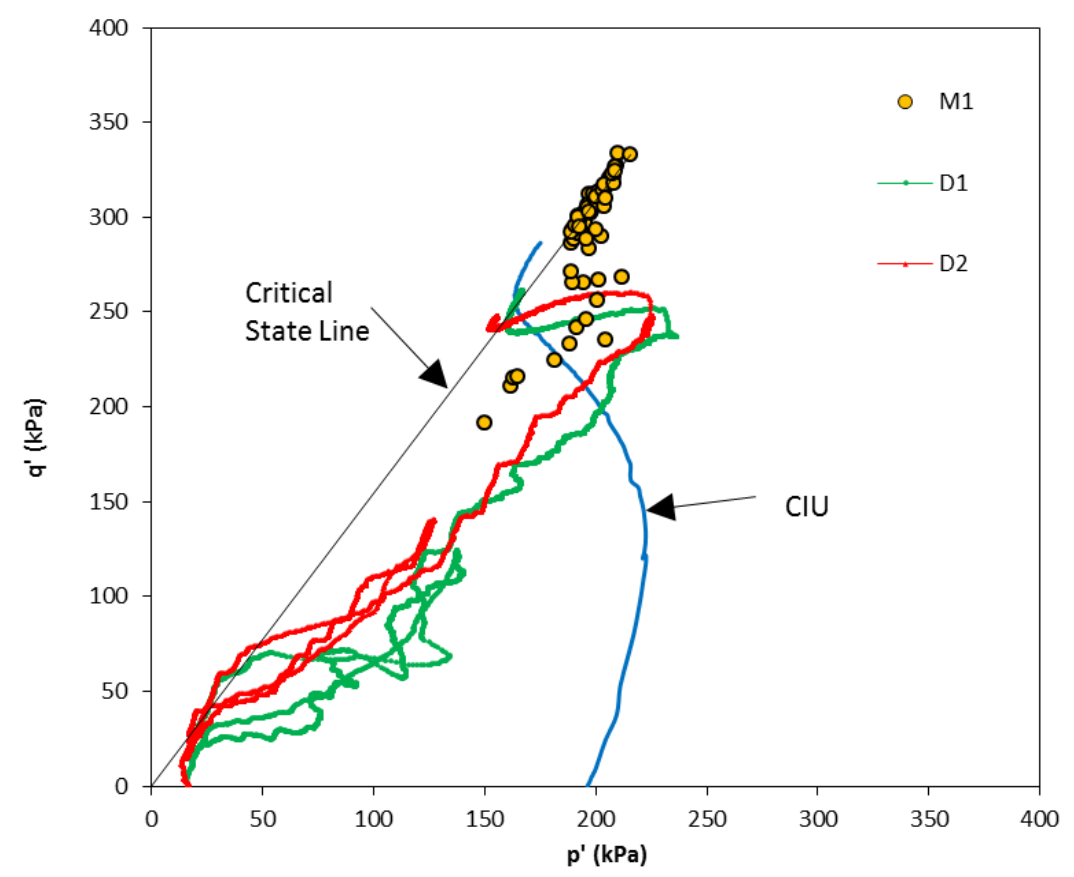

Fig. 8. Effective stress path.

After shearing, the soil specimen eventually reached the critical state. The equation for computing the effective frictional angle of resistance based on the stress invariants is shown in $\mathrm{Eq}(1)$.

$$
\begin{aligned}
\frac{q^{r}}{p^{r}}=\frac{6 \sin \phi^{\prime}}{3-\sin \emptyset^{r}} \\
K o=1-\sin \phi^{\prime}
\end{aligned}
$$

For M1 specimen, the effective frictional angle of resistance ( $\left.\phi^{\prime}\right)$ was found to be 37.8 degrees whilst the average $K o$ values obtained from the $K o$ consolidation test was 0.30 . A predicted $K o$ value was also computed in accordance with Jaky's equation, as presented in Eq (2), and then compared with the Ko value obtained directly from the experiment. The computed $K o$ value was found to be 0.386 . The small discrepancy could be caused by the fact that the soil specimen had not been satisfactorily saturated and the way of controlling the stress state of soil.

Similarly for the two saturated specimens (D1 and D2), the effective frictional angle of resistance was found to be 38.3 degrees, whereas the Ko values at normally consolidated state ranged from 0.37 to 0.39 . The predicted $K o$ value as computed in accordance with Eq (1) was 0.38 which was nearly identical to the experimental value. It seems that the residual soil tends to behave as sand considering the typical value of $K o$ and shear resistance. Also, the experimental results in the present study suggested that Jaky's equation could be used to predict the $K o$ value for the selected residual soil in Malaysia. This finding was indeed informative as many previous studies on loose sand reported that the computed Ko value somewhat deviated from the experimental Ko value to varying degrees [13-15], whereas the experimental result of Kaolin clay agreed well with Jaky's equation [17]. 


\section{Conclusion}

Following conclusions can be drawn from the present experimental study:

(1) The triaxial test setups and procedure employed herein can provide reasonable results and can be used to investigate the mechanical behaviour of soils. In specific, Ko consolidation and standard undrained compression tests can be used to examine the soil behaviours reasonably. The experimental results were comparable to the previous findings as reported by other researchers. With improvement on the double vacuuming saturation process, satisfactory degree of saturation could be achieved for the compacted residual soil.

(2) The behaviour of compacted residual soil having anisotropically-consolidated was found to be distinguished from the soil specimen being isotropically-consolidated. Under anisotropic consolidation, the soil experienced the natures of compression as well as shearing. The soil in CAU behaved as similar to those of over-consolidated clay (or dense sand), whereas the soil in CIU behaved as similar to the normally-consolidated clay (or loose sand).

(3) CAU test can favourably be used to reproduce the in-situ soil state under Ko condition in which the lateral strain becomes zero. From the experiment, the Ko values at normallyconsolidated state was found to be in the range of 0.3 to 0.4 . The $K o$ value obtained from the experiment was found to be in agreement with the predicted value as computed from the equation suggested by Jaky (1948).

\section{References}

1. J. Jaky, Proceedings of the 2nd International Conference on Soil Mechanics and Foundation Engineering, 1, 103-107 (1948)

2. B. B. K. Huat, D. G. Toll, A. Prasad, Handbook of Tropical Residual Soils Engineering (2017)

3. A. G. Salih, K. A. Kassim, EJGE, 17, 243-253 (2012)

4. H. Rahardjo, B. H. Ong, E. C. Leong, CAN GEOTECH J, 41, 421-436 (2004)

5. G. H. Meng, J. Chu, SOILS FOUND, 51, 565-573 (2011)

6. G. H. Meng, J. Chu, C. Klotz, 16 ${ }^{\text {th }}$ South East Asian Geotechnical Conference (2007)

7. R. Donaghe, F. Townsend, Geotechnical Testing Journal, 1, 173-189 (1978)

8. N. S. Rad, G. W. Clough, J GEOTECH ENG-ASCE, 110, 1205-1218 (1984)

9. S. K. Ampadu, F. Tatsuoka, SOILS FOUND, 33, 14-34 (1993)

10. Y. OKochi, F. Tatsuoka, SOILS FOUND, 24, 52-68 (1984)

11. Y. Tanaka, M. M. Lee, THE $69^{\text {th }}$ CGS CONFERENCE, GEOVANCOUVER 2016 (2016)

12. J. H. Atkinson, D. Richardson, P. J. Robinson, J GEOTECH GEOENVIRON, 113, 1468-1482 (1987)

13. J. Chu, C. L. Gan, Géotechnique, 54, 285-288 (2004)

14. D. Wanatowski, J. Chu, CAN GEOTECH J, 44, 1006-1012 (2007)

15. S.C.R. Lo, J. Chu, SOILS FOUND, 31, 181-187 (1991)

16. P. W. Mayne, F. H. Kulhawy, J GEOTECH ENG-ASCE, 108, 851-872 (1982)

17. J. H. Atkinson, P. L. Bransby, The Mechanics of Soils: An Introduction to Critical State Soil Mechanics (1978) 